distribution of attention. Finally, he claims that his hypothesis explains the apparent contradiction between the laws of Weber-Flexner and of Merkel.

\title{
Alfred Carver.
}

[ 34] Alcoholic insanity in the United States (La folie alcoolique aux Etatsunis).-Maurice Legrain. Ann. med.-psychol., 1923, lxxxi, 302.

ThIs.article examines the effects of prohibition on alcoholic insanity in the States which have adopted the measure.

The author begins by insisting that the law should have fair play, and that the numerous stories of drug-taking, crime and even alcoholism having largely increased since the introduction of the law should be taken cum grano salis. A consideration of many figures follows, some of them being sufficiently striking to reproduce. In 1913, for the thirteen State mental hospitals of New York, 572 persons were admitted for alcoholism, 438 men and 134, women. In 1920 this figure had fallen to 122,90 men and 32 women.

A study of figures relating to the admissions to the asylums of fourteen States shows that the proportion of admissions for alcoholic insanity is now only 1.9 per 100,000 population, compared with 6.7 in 1910 . Since 1920 there appears to have been a slight increase in male alcoholism, but not in female cases. M. Legrain explains this by pointing out that women are much less exposed to the activities of 'bootleggers.' In Massachusetts, in the 'dry' years 1920 and 1921, the number of women detained in penal institutions was the lowest for ten years. During these years the total prison population of Massachusetts was reduced by $\mathbf{5 2}$ per cent.

Interesting figures are given to show that alcoholic mental states occur in direct proportion to the consumption per head, and that since the States went 'dry' the most marked drop in alcoholic insanity has been among women.

The author becomes somewhat speculative after his display of impressive statistics. Among other interesting and suggestive comments he remarks that the American mind glories in success, especially material success; whereas in the ' wet' days to drink whisky was no particular sign of wealth, the 'dry' laws make whisky exceedingly costly, and therefore the rich drink it as a visible and outward sign of success!

G. W. B. J.

\section{TREATMENT.}

[ 35 ] The use and abuse of the relationship between doctor and patient in the practice of psychotherapy.-Mary C. Bell. Proc. Roy. Soc. Med. (Sect. Psychiat.), 1923, xvi, 12.

DuRING treatment the processes of projection and identification both take part in the relationship of the patient to the doctor; unrecognized attitudes and desires are projected on to the doctor from the basis of a positive or negative transference. The psychotherapeutist, too, tends to project his own unconscious wishes on to the patient, preventing him from seeing in him the same unconscious wishes. The analyst, therefore, must have his own uncon- 
scious desires brought to consciousness before he can be successful in dealing with his patient. In the purest form of psychoanalysis, where the physician acts as a mirror and where no discussion of the patient's problem takes place, the risk of projection by the analyst is small, but in the form of treatment by discussion or persuasion, and in the actual diagnosis of the situation, the unrecognized projection of the physician may play no inconsiderable part. The analyst must be willing to accept the transference as a temporary splint. The reactions of the patient are infantile, and until his vision is accommodated to the new conditions he needs must have a prop. As the analysis goes deeper the physician must welcome and encourage the growing independence of the patient. The relationship must be used as the pivot of the treatment, as the sensitizer for determining the measure of his progress. When the adaptations proceed the infantile attitude is replaced by an ordinary human relationship between the analyst and the patient. If the transference be kept as a pressure gauge between the two, it becomes an indicator of safety and forms no abnormal tie when the treatment is over.

C. W. Forsyth.

\section{[36] Active therapy in psychoanalysis.-Isador H. Coriot. Psycho- analytic Review, 1924, xi, 28.}

The author notes a new departure from the original technique of psychoanalysis. Under certain special conditions the analyst leaves his passive, sphinx-like attitude and actively interferes in the analysis. The indication for this is the stagnation of the analysis due to the patient's resistance. Neurosis is flight from painful reality, and the patient may unconsciously prolong the analysis in order to enjoy the pleasure of the transference. Dreams may also be used as a sort of refuge from hard reality ; religious trends may be stubbornly retained for the same end. Active therapy is an effort to make the patient feel the discomforts of his neurosis, and it endeavours to do this by instructing the patient to go where he will meet the exciting causes of his anxiety or his phobia. Only experienced analysts should attempt this variation of the usual technique, as instead of assisting the analysis it may, in inexperienced hands, result in increased resistance. Several examples of the method are given.

David Matthew.

\section{[37] Aseptic meningitis in combating the dementia præcox problem.-} R. S. Carroll. N.Y. Med. Jour., 1923, cxviii, 407.

AN account is given of five cases of dementia præcox treated by intratheca] injections of inactivated horse serum. 25 cc. of cerebrospinal fluid are withdrawn and an equal quantity of horse serum replaced. A minimum of two and a maximum of five injections produced either temporary or permanent lucidity in all the cases. Intrathecal injections of inactivated horse serum act by producing an active aseptic meningitis, noted in an increase in cell count in the cerebrospinal fluid up to about 100 per c.mm.

L. R. Yealland. 
[38] The effect of malarial fever upon dementia præcox subjects.-W. L. Templeton. Jour. of Ment. Sci., 1924, lxx, 92.

IT was considered that the empiricism which justified this treatment in general paralysis was quite as applicable to dementia præcox, particularly if one inclined to the toxæmic hypothesis of its etiology. Under sodium nucleinate therapy many cases of dementia præcox are said to have recovered completely and others to have shown very decided improvement. In all, twenty male cases were inoculated at intervals, and an average of twelve febrile reactions above $103^{\circ} \mathrm{F}$. allowed. Most of the cases showed some degree of mental improvement, even during the course of the fever. In a few there was no change, and this applied particularly to the paranoid type. The most striking change was seen in a brightening of intellectual interest, and in some a complete return to normal as far as could be judged. In some the improvement was preceded by a period of extreme irritability, but in no case was there any extreme excitement. At the end of two months there were few patients who had not materially lapsed, and it seems only a matter of time before all or most will have resumed their former mental state. It is considered that had an intensive scheme of manual occupational therapy been possible many of these might not have lapsed so quickly as they did. It is argued that the fleeting results of this treatment in dementia præcox, as opposed to the seemingly permanent improvement obtained in general paralysis, may be regarded as indirect evidence against the parasitic nature of the former.

C. S. R.

[39] The treatment of general paralysis by malaria inoculation (Über Malaria-impfbehandlung der Paralyse).-W. Weygandt. Klin. Woch., 1923, ii, 2164.

WE have here given us the results found from this treatment of general paresis in 300 patients. The method of Wagner-Jauregg was used. The writer classifies the cases into groups according as death resulted, no improvement, or improvement. He found that a large number of patients were enabled to take up their employment again, while improvement took place frequently, if only temporarily. Juvenile and malignant types were not affected in any way.

H. M. J.

[40] On the risks attending the treatment of general paralysis by inducing fever (Über Gefahren bei der Fieberbehandlung der Paralyse).P. Muhlexs. Klin. Woch., 1923, ii, 2340.

THE writer regards malaria inoculation in general paralysis as by no means free from harm, and emphasizes certain precautionary measures to obviate this useful method being called in question. It should only be used in hospitals free from parasitic insects. The patient's general condition should be good and quinine tolerance should be tested beforehand. Pure tertian malaria should be employed. Daily blood examination should take place. In marked malaria quinine should be administered without delay. A month 
should elapse after malarial infection ceases before the patient quits the hospital. A large number of the patients so treated remain well and employed for some years without relapsing.

H. M. J.

[41] The rôle of infection in the treatment of general paralysis.-W. M. McAlister. Jour. of Ment. Sci., 1924, lxx, 76.

THE writer concludes that the cases in which treatment by malarial infection has been most successful have been those in which it was undertaken early in the disease. It does not modify the laboratory findings. The malarial treatment seems to promise a retardation in the usual rate of deterioration. In some cases a more or less complete remission of the symptoms has been obtained. Of the two factors supposed to be at work, namely temperature and leucocytosis, temperature appears to play a larger part than the other. In another series of cases it was conclusively shown that, while a leucocytosis without temperature could readily be produced, the effect on the development of general paralysis was negligible. It may well be, however, that the treatment ultimately depends upon a biological factor, the malarial infection developing antibodies hostile to the spirochaete of syphilis. It is impossible to distinguish clinically natural remissions from those produced artificially.

C. S. R.

[ 42] Malaria therapy in general paralysis : being observations on fifty cases treated at the County Mental Hospital, Whittingham.-A. R. Grant and J. D. Silverston. Jour. of Ment. Sci., 1924, lxx, 81.

These investigators have come to the conclusion that this form of treatment is justified ; the technique is simple, and the artificial fever induced is easily, promptly and effectively controlled by the administration of quinine. Malaria relapses are rare. One attack of artificial malaria does not confer immunity to a second inoculation. Early cases offer the most hopeful prognosis. Complete remissions occur in all the-clinical types of the disease. The remissions are more pronounced and more frequent than those met with in untreated cases. In the majority of cases it arrests the progress of the disease and prolongs life. Recovery does not always take place promptly at the end of the malaria infection, but often slowly over an indefinite period of time. No case with an initial complete recovery had a relapse. Equally good results have followed malarial treatment only, without additional arsenical medication. In late cases there has been definite improvement physically, whilst some have recovered sufficiently in their mental balance to be allowed home to the care of their friends.

C. S. R. 